\title{
Canadian dairy farmers' perception of the efficacy of biosecurity practices
}

\author{
J. Denis-Robichaud, ${ }^{1}$ D. F. Kelton, ${ }^{2}$ C. A. Bauman, ${ }^{2}$ H. W. Barkema, ${ }^{3}$ G. P. Keefe,${ }^{4}$ and J. Dubuc ${ }^{5 *}$ \\ ${ }^{1}$ Independent researcher, Amqui, QC, Canada, G5J 2N5 \\ ${ }^{2}$ Department of Population Medicine, University of Guelph, Guelph, ON, Canada, N1G 2W1 \\ ${ }^{3}$ Department of Production Animal Health, University of Calgary, Calgary, AB, Canada, T2N 1N4 \\ ${ }^{4}$ Department of Health Management, University of Prince Edward Island, Charlottetown, PE, Canada, C1A 4P3 \\ ${ }^{5}$ Département de sciences cliniques, Faculté de médecine vétérinaire, Université de Montréal, 3200, rue Sicotte, St-Hyacinthe, QC, \\ Canada, J2S 2M2
}

\section{ABSTRACT}

The adoption of biosecurity practices on dairy farms is limited worldwide. Multiple aspects, one of which is the perception of the effectiveness of these practices, influence the adoption of preventive behavior. The objectives of the present study were to investigate the general understanding of biosecurity by Canadian dairy farmers and to describe their perception of the effectiveness of specific biosecurity practices. In 2015, 368 Canadian dairy farmers were selected to participate in an on-farm national cross-sectional benchmarking study during which they were asked about their general understanding of biosecurity and their perception of the effectiveness of 17 practices to minimize biosecurity risk. For these same biosecurity practices, respondents were asked whether they discussed that particular practice with a veterinarian and whether they implemented it on their farm. Herd and respondent characteristics were also recorded. Associations between the perception of effectiveness of each biosecurity practice and the discussion with a veterinarian, its implementation on farm, and the herd and respondent characteristics were examined using ordered regression models. Most respondents thought the purpose of on-farm biosecurity was to prevent both entry of a new pathogen and spread of an existing pathogen (73\%) and considered general biosecurity to be effective $(92 \%)$ and important (58\%). When asked about specific biosecurity practices, respondents considered most of them to be effective (60-94\%). Practices related to direct animal-to-animal contact were perceived as effective by more respondents than biosecurity practices related to fomites and visitors. Less than $20 \%$ of the respondents reported discussing the different biosecurity practices with a veterinarian, and less than $60 \%$ reported implement-

Received January 16, 2019.

Accepted June 29, 2019.

*Corresponding author: jocelyn.dubuc@umontreal.ca ing these practices on their farm. Geographical region, involvement of a veterinarian, and implementation of the practice on farm were associated with the perception of effectiveness for multiple practices. Finally, the reasons chosen by most respondents as motivation to implement biosecurity practices were (1) if the practice helped to regionally prevent the introduction or the spread of a disease and (2) if it was proven to be beneficial to the health and welfare of animals. These results show that there is a positive perception of the effectiveness of specific biosecurity practices, that there might be a lack of understanding of the practices involving transmission of diseases via indirect contact, and that the perceived threat associated with not adopting practices is minimal.

Key words: effectiveness, adoption, motivation, veterinarian

\section{INTRODUCTION}

On-farm biosecurity for animal production aims to prevent the spread of contagious diseases within and between herds and, ultimately, to contribute to public health and food safety (Dargatz et al., 2002; Gunn et al., 2008). Adoption of biosecurity practices on dairy farms, however, has been reported to be limited in multiple studies (Moore et al., 2010; Sarrazin et al., 2014; Emanuelson et al., 2018). According to the concept of the health belief model (Janz and Becker, 1984; Jansen and Lam, 2012; Ritter et al., 2017), adoption of preventive health behaviors is determined by belief in a personal threat (influenced by perceived susceptibility and severity) and belief in the effectiveness of the preventive behavior (influenced by perceived benefits and barriers). Multiple aspects of this model as well as the farmers' context have been suggested to play a role in the adoption of biosecurity practices (Ritter et al., 2017).

The threat of infectious diseases recognized by farmers is limited. They perceive the risk of introduction 
of diseases as low (Heffernan et al., 2008; Nöremark et al., 2010; Kristensen and Jakobsen, 2011), and they perceive the adoption of biosecurity practices as useless if it is not uniform across the industry (Gunn et al., 2008; Heffernan et al., 2008). To overcome this mindset, invoking legislation and the implementation of better communication of information about diseases and disease transmission have been suggested (Heffernan et al., 2008; Nöremark et al., 2010). Veterinarians raised similar concerns, noting that farmers associate diseases with external aspects that are out of their control instead of focusing on the control over disease spread on their individual farm (Shortall et al., 2016).

In the health belief model, perceived effectiveness of a preventive behavior such as biosecurity is the result of the perception of benefits greater than the barriers to its implementation (Janz and Becker, 1984; Jansen and Lam, 2012). Stakeholders in the dairy industry reported many barriers to implementation of biosecurity practices by farmers, including limited money and time and suboptimal on-farm infrastructure and management systems to support biosecurity (Shortall et al., 2016). The perception of benefits and barriers contributing to perceived effectiveness was presented for different biosecurity practices by Shortall et al. (2017). The benefits were defined as the capacity to prevent the spread of disease-causing agents onto and within the farm ("effectiveness"), and the barriers were defined as the ease of implementation by the farmer ("practicality"). The 30 practices examined in the study showed that there were perception disparities between different respondents (farmers, veterinarians, and other stakeholders) but also between biosecurity practices. For example, practices involving knowledge, planning, veterinary involvement, and vaccination were perceived as both efficient and practical, and practices related to isolating or quarantining animals were all perceived as impractical (Shortall et al., 2017).

Although current information on the perception of biosecurity practices in European countries is available, the animal production practices and disease occurrence in a country or a region can influence this perception (Ritter et al., 2017). The Canadian dairy industry is moving toward adoption of compulsory national standards for biosecurity (CFIA, 2013); therefore, a better understanding of drivers and barriers to adoption of biosecurity practices is necessary. A Canadian study has already described the different views that dairy farmers have toward on-farm Johne's disease prevention and control (Ritter et al., 2016). This study provided information on the perception of dairy farmers of the importance of prevention and control strategies and their belief in the effectiveness of these proposed strategies for Johne's disease control. It is unclear, however, if the attitude toward the biosecurity practices for a specific disease is generalizable to all practices for all diseases. Consequently, the objectives of this paper were to investigate the understanding of biosecurity by Canadian dairy farmers and to describe their perception of the effectiveness of general biosecurity and specific biosecurity practices.

\section{MATERIALS AND METHODS}

This study was part of the Canadian National Dairy Study surveying multiple aspects of dairy farm management, which was approved by Human Ethics and Animal Care Committees of each participating University: University of Calgary (REB\#14-2481, AC15-0048), University of Guelph (REB\#14DC025, AUP\#3320), Université de Montréal (15-007-CE-RESD, 15-Rech-1786), University of Prince Edward Island (REB\#6006095, AUP\#15-106), and University of Saskatchewan (AUP\#20150037). The 2 parts of this study were thoroughly described previously (Bauman et al., 2018). Briefly, phase I was an extensive 189-question questionnaire developed by experts across Canada. Every licensed dairy producer in Canada was invited to participate via a letter and was offered various means of access to the survey in both English and French: an online platform (Qualtrics; http://www.qualtrics.com/, a paper questionnaire by mail (paid postage), and a verbal questionnaire over the phone (toll-free number). In phase II, farms were selected from the 1,157 respondents to phase I following a stratified random sampling scheme by province and participation or not in milk recording. A total of 374 farms (5 in Newfoundland, 20 in Prince Edward Island, 17 in New Brunswick, 18 in Nova Scotia, 121 in Québec, 133 in Ontario, 10 in Manitoba, 10 in Saskatchewan, 20 in Alberta, and 20 in British Columbia) were visited based on the calculated sample size for the Canadian National Dairy Study, the costs of travel to more remote regions, and the sampling staff available. Farm visits were carried out by 14 university students between May 10 and August 30, 2015. The assessors received standardized training over $3 \mathrm{~d}$ on farm selection, questionnaire administration, sample collection, and animal assessment. During the visit, a questionnaire was administered by the assessors covering 5 subcategories: biosecurity, antimicrobial use, calf health, down cow management, and the role of veterinarians on the farm. Although the National Dairy Study included questions on diverse subjects, the present paper reports on the results from a subset of 20 questions about the producers' understanding of biosecurity and their perception of the effectiveness of practices to minimize biosecurity risk (disease entry and spread within the herd; see Supplemental File 
S1, https://doi.org/10.3168/jds.2019-16312). Briefly, 2 were multiple-choice questions with a single-answer option (1 open-ended with text entry option), 1 was a multiple-choice question with a multiple-answer option (with text entry option), and 17 were 4-point ordinal scale questions (respondents selected how effective practices were for minimizing biosecurity risk: not effective, not sure if it would be effective, can be very effective, or very effective). For the same biosecurity practices, respondents were asked whether they discussed that particular practice with a veterinarian and whether they implemented it on their farm.

Herd and respondent characteristics were also collected. Geographical region was categorized into Western provinces (British Columbia, Alberta, Saskatchewan, and Manitoba), Ontario, Québec, and Eastern provinces (New Brunswick, Nova Scotia, Prince Edward Island, and Newfoundland). The monthly volume of shipped milk was used to categorize farms using the interquartile ranges because it was the most reliable data available. Milk production was categorized as very small $(<27,000 \mathrm{~kg} / \mathrm{mo})$, small $(27,000-40,000 \mathrm{~kg} / \mathrm{mo})$, medium $(40,000-63,000 \mathrm{~kg} / \mathrm{mo})$, and large $(>63,000$ $\mathrm{kg} / \mathrm{mo}$ ). Housing for lactating cows was categorized as tiestall or loose (including freestall and bedded pack) housing. Respondents were categorized by age group ( $<30$ yr, 30-39 yr, 40-49 yr, 50-59 yr, and $\geq 60 \mathrm{yr}$ ) and level of education (high school, college, and university).

Statistical analyses were conducted using $\mathrm{R}$ version 3.4.3 (R Core Team, 2015). Frequencies were calculated for categorical variables. The perception of effectiveness of each biosecurity practice was examined using ordered multinomial regression models adjusted for heteroscedasticity (oglmx package). First, univariable associations between each practice and the involvement of a veterinarian (discussion), its implementation on farm, and the herd and respondent characteristics were assessed. Second, multivariable models were built by including the geographical region as a fixed clustering effect and adding potential confounders (herd size, type of housing, age and level of education of the respondent, discussion of the practice with a veterinarian, and implementation of the practice) in turn and keeping the ones with a $P$-value $<0.20$ (Maldonado and Greenland, 1993). Collinearity was tested among the variables remaining in each model, and only the most plausible variable was kept in the model in case of highly collinear variables (odds ratio >8; Dohoo et al., 2009). Finally, only the multivariable models containing variables with a $P$-value $<0.05$ were kept in the results. The results are presented as the marginal effect $( \pm$ SEM) on the probability of the participants in each category to select each perception (not effective, not
Table 1. Proportion of respondents classified by demographic variables (geographical region, type of housing, herd milk production, age, and highest level of education) who completed the biosecurity section of an on-farm questionnaire administered to Canadian dairy producers $(\mathrm{n}=368)$

\begin{tabular}{|c|c|c|}
\hline Variable & $\mathrm{n}$ & $\%^{1}$ \\
\hline \multicolumn{3}{|l|}{ Geographical region } \\
\hline Western provinces ${ }^{2}$ & 55 & 15.0 \\
\hline Ontario & 133 & 36.1 \\
\hline Québec & 121 & 32.9 \\
\hline Eastern provinces ${ }^{3}$ & 59 & 16.0 \\
\hline \multicolumn{3}{|l|}{ Type of housing } \\
\hline Tiestall & 165 & 45.0 \\
\hline Loose & 202 & 55.0 \\
\hline \multicolumn{3}{|l|}{ Herd milk production, $\mathrm{kg} / \mathrm{mo}$} \\
\hline Very small $(<27,000)$ & 53 & 15.2 \\
\hline Small $(27,000-40,000)$ & 75 & 21.6 \\
\hline Medium $(40,000-63,000)$ & 86 & 24.7 \\
\hline Large $(>63,000)$ & 134 & 38.5 \\
\hline \multicolumn{3}{|l|}{ Age of respondent, yr } \\
\hline$<30$ & 59 & 16.1 \\
\hline $30-39$ & 101 & 27.6 \\
\hline $40-49$ & 81 & 22.1 \\
\hline $50-59$ & 102 & 27.9 \\
\hline$\geq 60$ & 23 & 6.3 \\
\hline \multicolumn{3}{|l|}{ Highest level of education achieved } \\
\hline Primary, middle, or high school & 122 & 33.3 \\
\hline College diploma or degree & 191 & 52.2 \\
\hline University or postgraduate degree & 53 & 14.5 \\
\hline
\end{tabular}

${ }^{1}$ Sum of the categories within a variable and within a column equals $100 \%$.

${ }^{2}$ British Columbia, Alberta, Saskatchewan, and Manitoba.

${ }^{3}$ New Brunswick, Nova Scotia, Prince Edward Island, and Newfoundland.

sure if it would be effective, can be very effective, or very effective).

\section{RESULTS}

The biosecurity section was not completed by 6 respondents who were not involved in the biosecurity management on the farm, and the demographic data of the 368 respondents are presented in Table 1 . The number of answers per question varied as respondents were allowed to skip questions. Biosecurity questions were answered by $94 \%(\mathrm{n}=346)$ to $98 \%(\mathrm{n}=361)$ of the respondents.

Respondents were first asked to choose from among statements describing what they thought the purpose of general on-farm biosecurity was. Most respondents (73\%) answered that it was to prevent both entry of a new pathogen and spread of an existing pathogen, whereas $22 \%$ answered it was only to prevent entry of a new pathogen onto a farm and $4 \%$ responded that it was only to prevent spread of an already-existing pathogen on the farm to other animals through direct and indirect contact. Some respondents (1\%) also mentioned that it included practices to prevent an existing 


\section{Effectiveness}

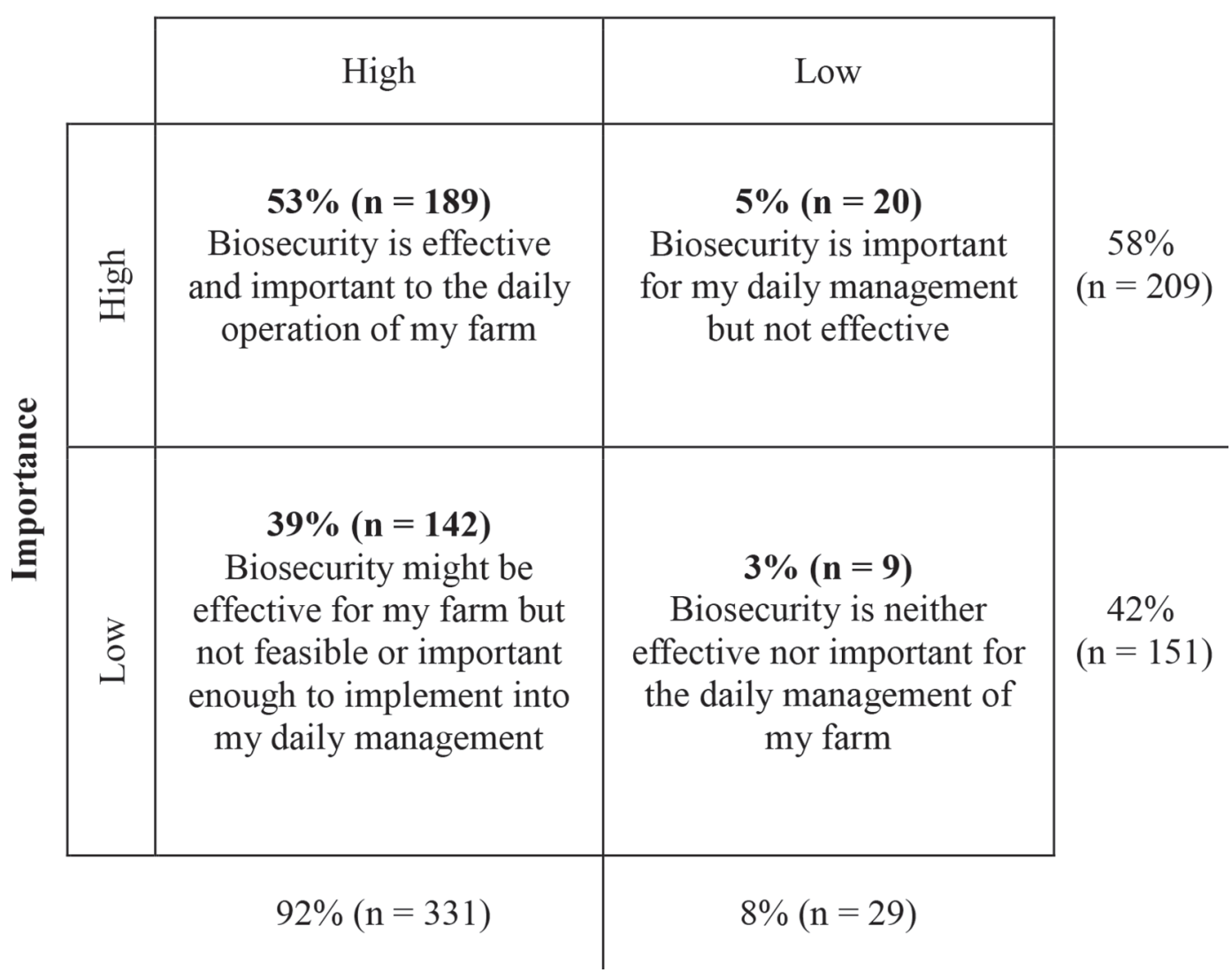

Figure 1. A 2-by-2 table representing the perception of importance and effectiveness of general biosecurity of Canadian dairy farmers. Respondents had to choose between 4 statements that each stated importance and effectiveness (see Supplemental File S1, https://doi.org/10 .3168/jds.2019-16312). Their answers were then recategorized as considering the importance and effectiveness of biosecurity as low and high.

pathogen from leaving the farm (which in some systems is termed "biocontainment"). When respondents had to choose from among statements reflecting their perception of the importance and effectiveness of general biosecurity, more than half (53\%) considered biosecurity to be both important and effective (Figure 1); most respondents (92\%) thought biosecurity was effective, whereas $58 \%$ thought it was important (Figure 2).

For most of the specific biosecurity practices, between 60 and $94 \%$ of the respondents perceived it was very effective or can be very effective to minimize disease entry into a dairy farm and spread within the herd (Figure 3). Less than $40 \%$ of the respondents, however, believed that "encouraging vehicles to park away from the barn area" and "having a visitor log" are very effective or can be very effective. The 17 biosecurity practices investigated were discussed with a veterinarian by 1 to $20 \%$ of the respondents (median $=3 \%$ ) and were implemented on 3 to $58 \%$ of the farms (median $=$ $16 \%$; Figure 4).
The marginal effects of all of the statistically significant multivariable models are presented in Supplemental Tables S1 through S4 (https://doi.org/10.3168/jds .2019-16312), and Figures 5, 6, 7, 8, and 9 graphically represent some of these models. In summary, the uptake of the various practices was associated with the perception of effectiveness and the involvement of a veterinarian. In general, respondents who perceived a practice as very effective were more likely to implement it on their farm than respondents who perceived it as ineffective (Figures 5-9). There were some regional differences in uptake, and it was challenging to pinpoint trends overall among the 17 different practices. Involvement of a veterinarian was also associated with the perception of the effectiveness of multiple biosecurity practices to minimize disease entry and spread within the herd. Respondents who discussed a practice with a veterinarian more often perceived this practice as very effective compared with respondents who did not (Figures 8 and 9). 


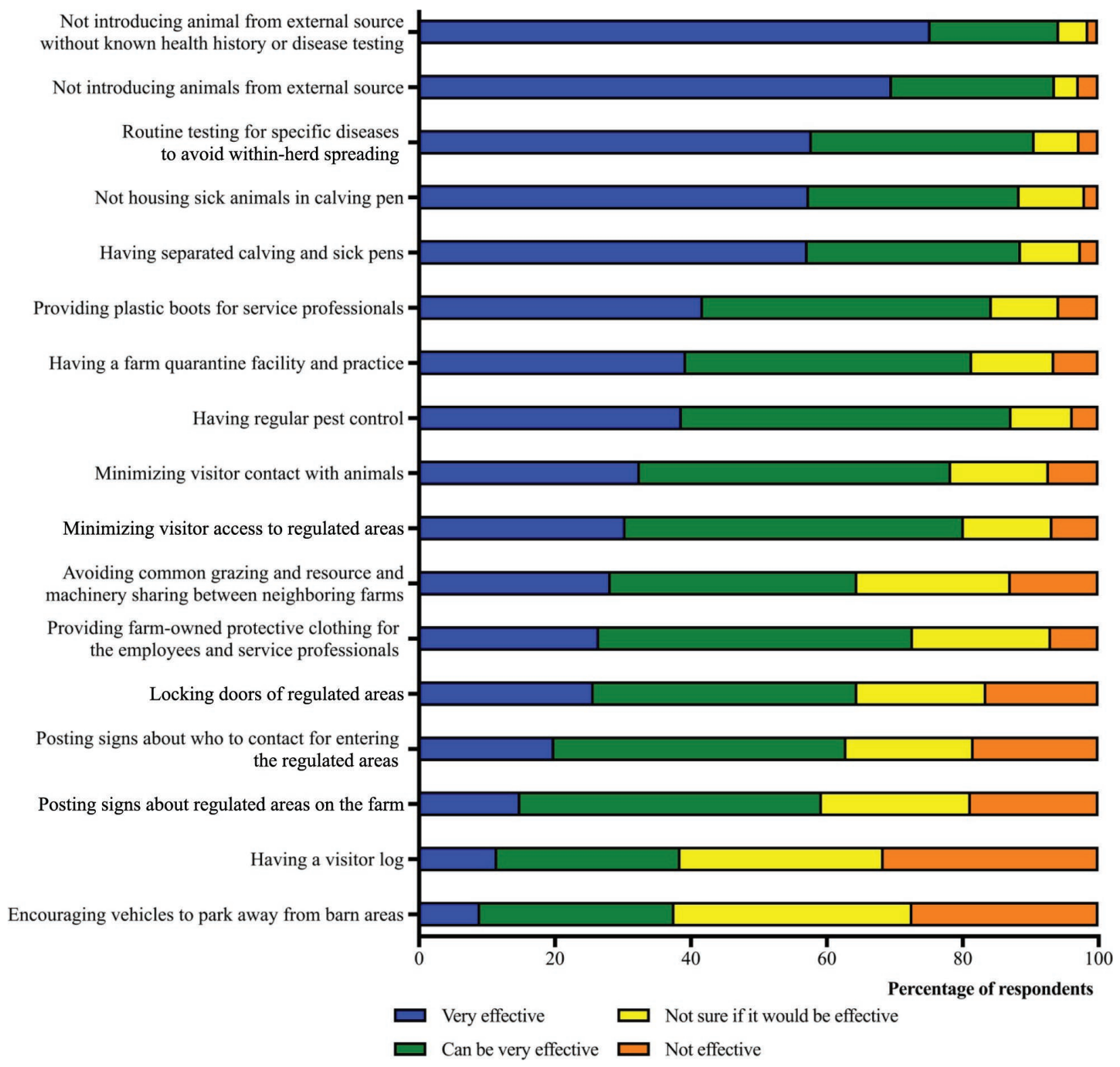

Figure 2. Perception of effectiveness of 17 specific biosecurity practices to prevent disease entry and spread within the herd by 359 Canadian dairy farmers participating in the Canadian National Dairy Study. "Regulated areas" were conveyed by the assessors as areas where contact with animals was possible.

Some biosecurity practices were associated with demographic characteristics of the respondents. For example, respondents with a university degree more often perceived having a quarantine plan as very effective than respondents with a college or high school degree (Figure 5), and respondents with large milk production $(>63,000 \mathrm{~kg} / \mathrm{mo})$ more often perceived providing plastic boots for service professionals as very effective than respondents with very small to medium milk production $(\leq 63,000 \mathrm{~kg} / \mathrm{mo}$; Figure 6$)$.
Finally, when respondents were asked what could motivate them to implement a biosecurity practice on their farm, $40 \%$ selected all the items offered to them. The reasons more often selected were (1) if it helped to regionally prevent the introduction or the spread of a disease $(22 \%)$ and (2) if it was proven to be beneficial to the health and welfare of animals (22\%), followed by (3) if there was an economic impact on their farm (20\%), (4) if it increased milk sales (19\%), and (5) if there was a mandatory legislation $(17 \%)$. 


\section{DISCUSSION}

In the present study, Canadian dairy farmers perceived most of the specific biosecurity practices as effective for minimizing disease entry and spread within a dairy farm, which is similar to what was reported by Shortall et al. (2017). Moreover, biosecurity practices preventing direct animal-to-animal contact were perceived as effective by more respondents than practices involving indirect contact (e.g., equipment and visi- tors), which was also reported by Shortall et al. (2017). For example, practices considered effective by the most respondents were associated with controlling animal movement ("not introducing animals from external sources without known health history or disease testing" and "not introducing animals from external sources"). Similarly, Shortall et al. (2017) reported that "maintain a closed herd," "test new animals bought onto the farm to assess their disease status," and "verify the disease status of bought-in animals by viewing accredited

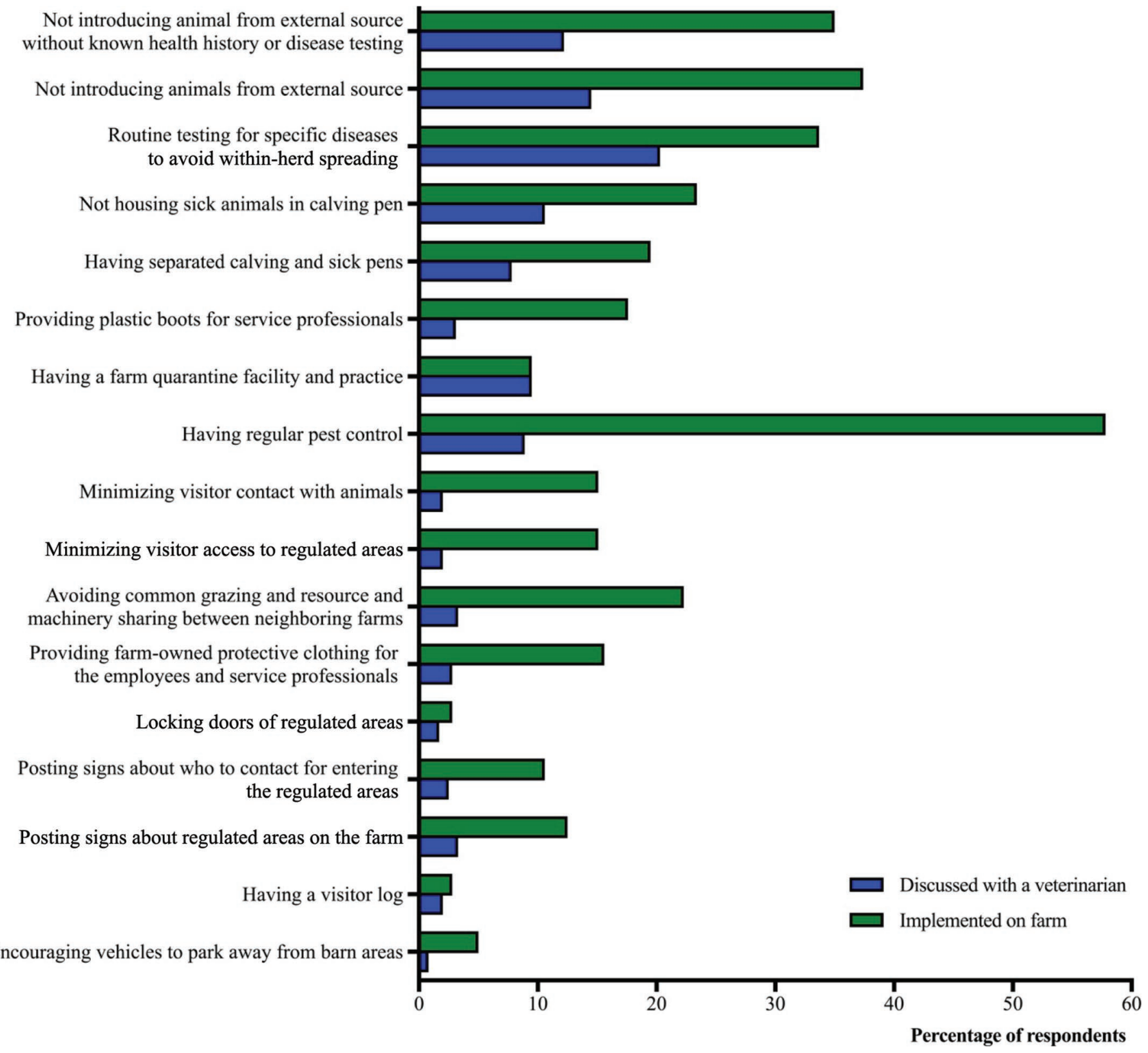

Figure 3. Involvement of a veterinarian (discussion) and implementation of 17 specific biosecurity practices by 359 Canadian dairy farmers. "Regulated areas" were conveyed by the assessors as areas where contact with animals was possible. 


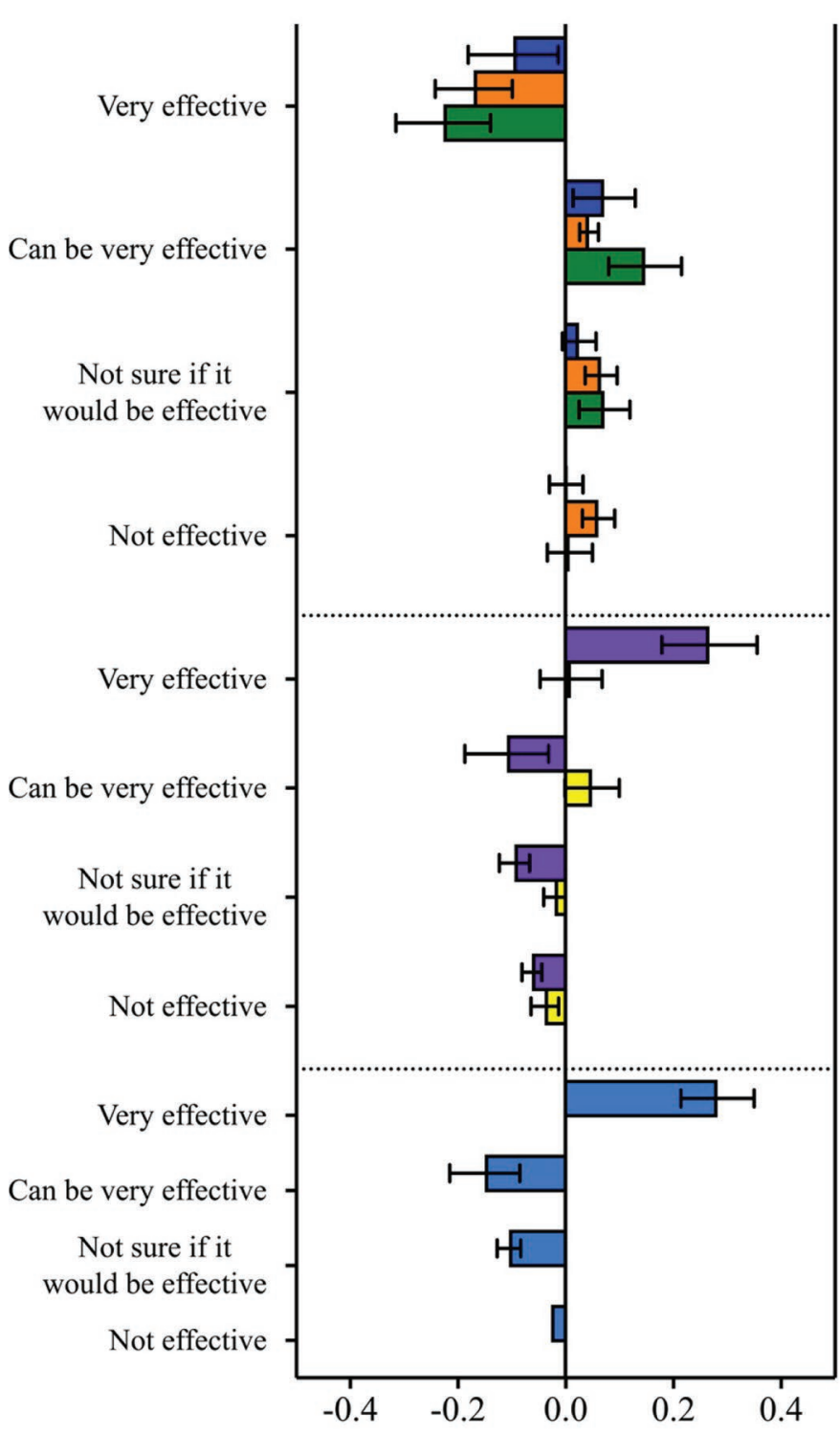

Relative perception of effectiveness

\author{
Geographical region \\ Eastern provinces ${ }^{1 *}$ \\ Québec
}

$\square$ Ontario

$\square$ Western provinces ${ }^{2}$

\section{Respondent's education level ${ }^{\mathrm{a}}$}

High school*

$\square$ College

๑ University

\section{*Reference category \\ ${ }^{\mathrm{a}}$ Adjusted for geographical region \\ ${ }^{\mathrm{b}}$ Adjusted for herd size and respondent's education level \\ ${ }^{1}$ New Brunswick, Nova Scotia, Prince Edward Island, and \\ Newfoundland \\ ${ }^{2}$ British Columbia, Alberta, Saskatchewan, and Manitoba}

Figure 4. Perception of effectiveness of having a farm quarantine facility and practice by geographical region $(P=0.04)$, respondent's education level $(P=0.01)$, and implementation status on the farm $(P<0.01)$. Marginal effects $( \pm$ SEM $)$ were obtained from heteroskedastic ordered multivariable regression models adjusted for confounders and clustering by geographical region.

results" were part of the practices perceived as most effective. Additionally, practices in the present study related to controlling visitor access to the farm and animals were considered effective by fewer respondents. Shortall et al. (2017) also reported that "minimizing the number of visitors entering the farm" was perceived as the least-effective practice. Although the study by
Shortall et al. (2017) included only expert farmers, who considered biosecurity and disease control on-farm to be a key priority, the present study found multiple similarities to that study in the farmers' perceptions of the effectiveness of specific biosecurity practices.

For most biosecurity practices evaluated in the present study, respondents who perceived a given practice 
as effective were more likely to have implemented it on their farm than respondents who perceived it as not effective. The study design did not allow us to identify whether this association is due to farmers adopting a practice because they think it is effective, farmers thinking the practice is effective after adopting it, or both. Regardless of this association, there is a discrepancy between the perception and the adoption of biosecurity practices, as biosecurity practices were implemented by $<40 \%$ of the respondents (except for "having regular pest control"). This disconnect between perception and action was previously observed in Dan-

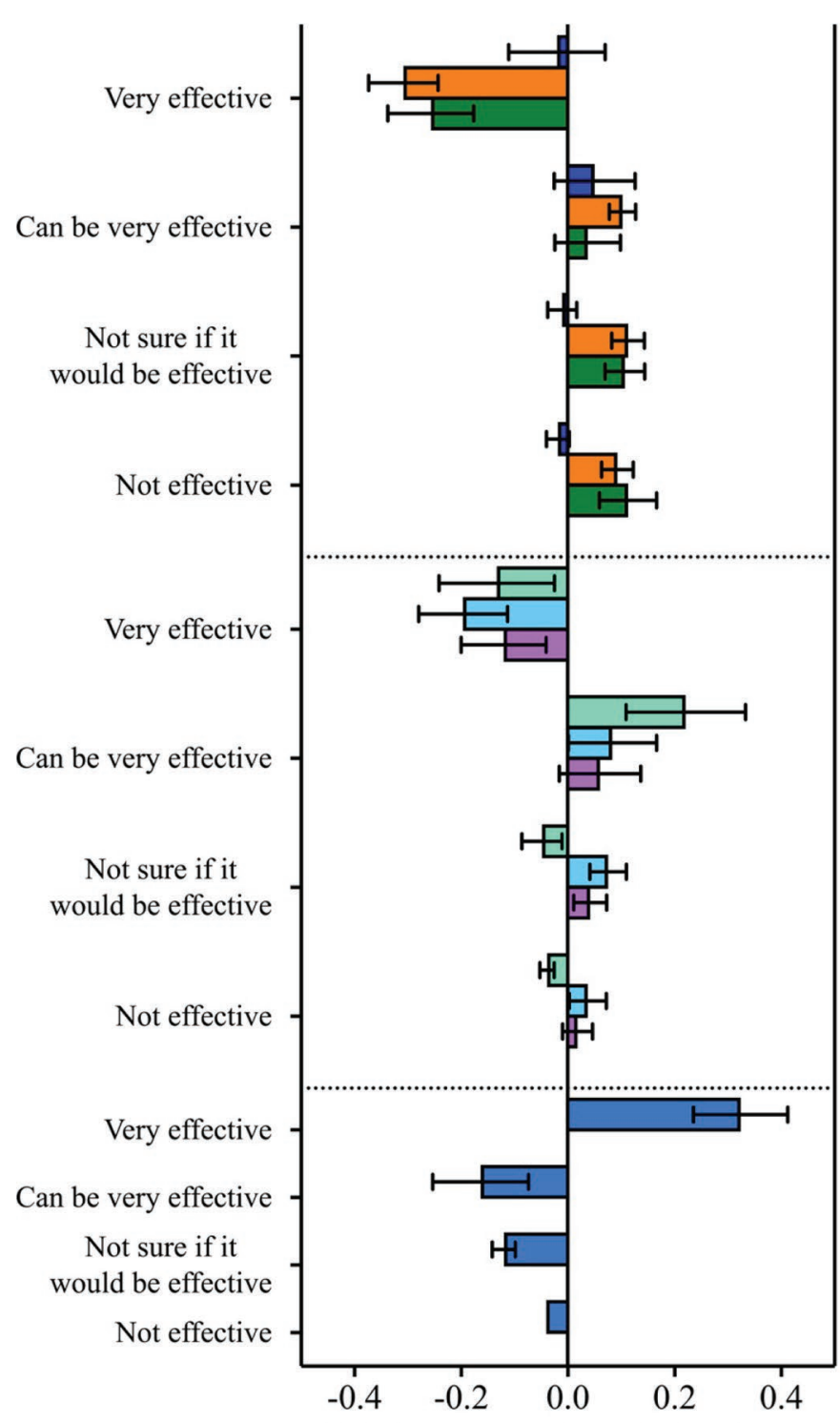

Relative perception of effectiveness

\section{Geographical region}

Eastern provinces ${ }^{1 *}$

Q Québec

$\square$ Ontario

$\square$ Western provinces ${ }^{2}$

Herd size $^{\text {a }}$

Large (>100 cows)*

$\square$ Medium (66 to 100 cows)

$\square$ Small (45 to 65 cows)

口 Very small ( $<45$ cows)

\section{Implementation status ${ }^{\text {ab }}$}

Not implemented*

Implemented

\section{*Reference category

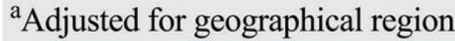 \\ ${ }^{b}$ Adjusted for type of housing and herd size \\ ${ }^{1}$ New Brunswick, Nova Scotia, Prince Edward Island, and \\ Newfoundland \\ ${ }^{2}$ British Columbia, Alberta, Saskatchewan, and Manitoba}

Figure 5. Perception of effectiveness of providing plastic boots for service professionals by geographical region $(P<0.01)$, herd size $(P=$ $0.02)$, and implementation status on the farm $(P<0.01)$. Marginal effects $( \pm$ SEM $)$ were obtained from heteroscedastic ordered multivariable regression models adjusted for confounders and clustering by geographical region. 


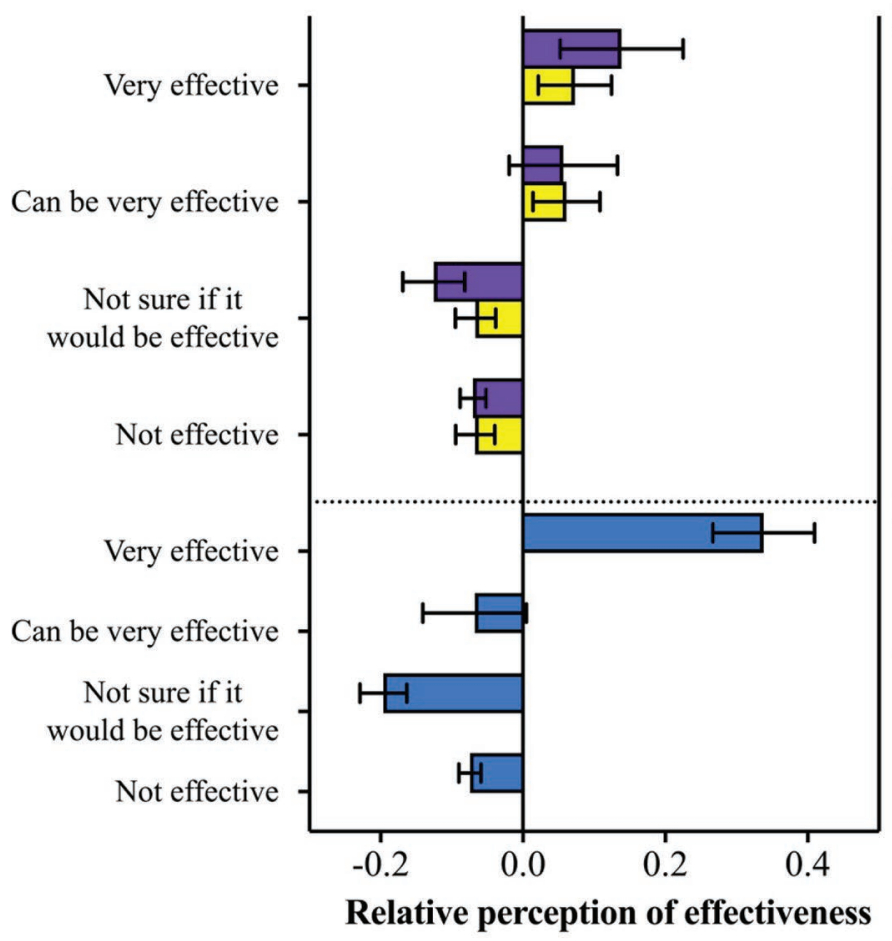

\author{
Respondent's education level ${ }^{\mathrm{a}}$ \\ High school* \\ $\square$ College \\ University \\ Implementation status ${ }^{b}$ \\ Not implemented* \\ $\square$ Implemented \\ *Reference category \\ ${ }^{a}$ Adjusted for geographical region \\ bAdjusted for respondent's \\ education level
}

Figure 6. Perception of effectiveness of providing farm-owned protective clothing for the employees and service professionals by respondent's education level $(P=0.01)$ and implementation status on the farm $(P<0.01)$. Marginal effects $( \pm$ SEM $)$ were obtained from heteroscedastic ordered multivariable regression models adjusted for confounders and clustering by geographical region.

ish and English dairy farmers as well (Kristensen and Jakobsen, 2011; Brennan and Christley, 2013). In these studies, farmers perceived practices such as having an open herd as risky or perceived biosecurity practices such as a closed herd as effective but did not adopt these practices. This dissonance could be explained by the perceived impracticality of implementing some biosecurity practices (Sayers et al., 2014; Shortall et al., 2017 ) and the perception of low risks associated with infectious diseases (Nöremark et al., 2010). The latter seems to be more likely in the present study because respondents most frequently chose "if it helps to regionally avoid the introduction or the spread of a disease" and "if it's proven to be beneficial to the health and welfare of animals" as a motivation to implement a practice, suggesting that they may connect adoption of biosecurity practices with broader risk rather than risk to their own herd.

Farmers' disease awareness was also mentioned by veterinary experts as the most effective and practical biosecurity measure on cattle farms (Kuster et al., 2015). Veterinarians also thought that they should promote biosecurity in dairy farms, but only half of the veterinarians who answered reported regularly advising their client on biosecurity (Sayers et al., 2014).
In the present study, however, less than one-quarter of the respondents reported discussing the different biosecurity practices with a veterinarian, which suggests a limited involvement of the Canadian veterinarians. Yet respondents who discussed a biosecurity practice with a veterinarian were more likely to perceive this practice as effective than respondents who did not. In 2019, elements of the national standard for biosecurity will be compulsory via the Dairy Farmers of Canada proAction program (DFC, 2018), under which the individual farm biosecurity plan will have to be developed in consultation with multiple stakeholders, including the herd veterinarian (CFIA, 2013). This will increase the involvement of veterinarians in on-farm biosecurity and probably increase the perceived effectiveness of biosecurity by dairy farmers.

The respondents with a higher level of education more often perceived some indirect biosecurity practices as effective. It is possible that better awareness and understanding of disease transmission by farmers with higher education has influenced their perception of the effectiveness of the indirect practices. This could also be linked to a greater disease awareness and sense of responsibility. As the present study showed, education seems to be marginally influential on the perception of 


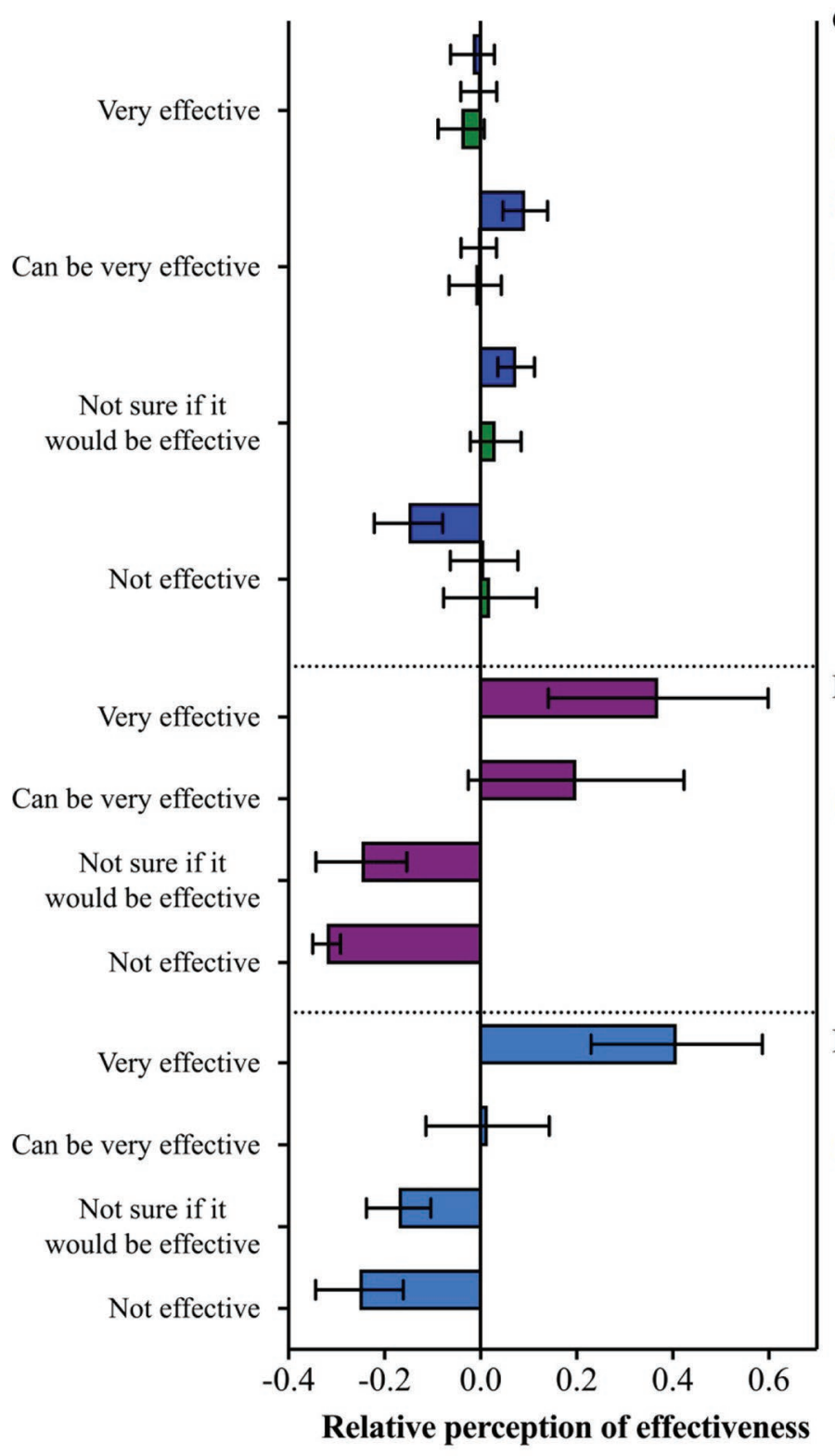

\author{
Geographical region \\ Eastern provinces ${ }^{1 *}$ \\ Québec \\ 口 Ontario \\ Western provinces ${ }^{2}$
}

\title{
Involvement of the veterinarian ${ }^{\mathrm{a}}$
}

Not discussed*

$\square$ Discussed

\section{Implementation status ${ }^{\mathrm{ab}}$}

Not implemented*

$\square$ Implemented

\begin{tabular}{|c|}
\hline *Reference category \\
\hline geographi \\
\hline${ }^{\mathrm{b}}$ Adjusted for herd size \\
\hline $\begin{array}{l}{ }^{1} \text { New Brunswick, Nova Scotia, } \\
\text { Prince Edward Island, and } \\
\text { Newfoundland }\end{array}$ \\
\hline $\begin{array}{l}{ }^{2} \text { British Columbia, Alberta, } \\
\text { Saskatchewan, and Manitoba }\end{array}$ \\
\hline
\end{tabular}

Figure 7. Perception of effectiveness of having a visitor log by geographical region $(P=0.05)$, involvement of the veterinarian $(P=0.01)$, and implementation status on the farm $(P=0.01)$. Marginal effects $( \pm$ SEM) were obtained from heteroscedastic ordered multivariable regression models adjusted for confounders and clustering by geographical region.

effectiveness, but only for certain factors; this was also its effect on adoption of preventive strategies (Ritter et al., 2017).

Perception of the effectiveness of most biosecurity practices did differ among the 4 regions of Canada. However, the difference among regions with respect to effectiveness perception varied among the practices. This could possibly be explained by the different pro- duction and management practices as well as cultural differences observed in different regions (e.g., perception of animal welfare, environmental, and agricultural issues), similar to what might be observed in different European countries (Kristensen and Jakobsen, 2011; Brennan and Christley, 2013; Shortall et al., 2017). The Canadian dairy industry is unique in that it has a supply management system that controls the national 


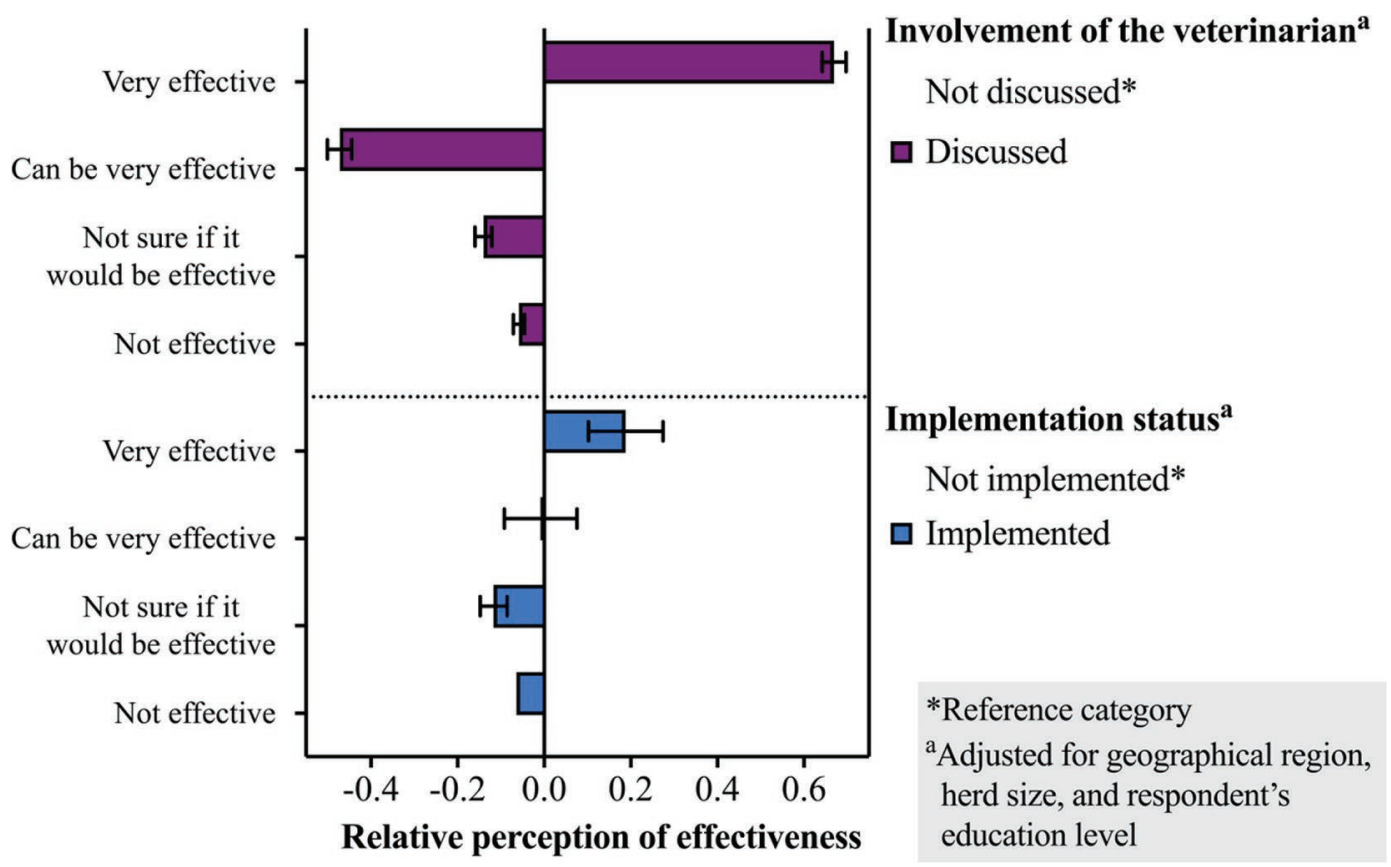

Figure 8. Perception of effectiveness of minimizing visitor contact with animals by involvement of the veterinarian $(P=0.01)$ and implementation status on the farm $(P<0.01)$. Marginal effects $( \pm$ SEM $)$ were obtained from heteroscedastic ordered multivariable regression models adjusted for confounders and clustering by geographical region.

production of milk by the establishment of quotas, managed at the provincial level (Canadian Dairy Commission, 2016). Consequently, there is only 1 milk buyer in each province, which is likely to result in a more homogeneous population of farms as industry initiatives delivered by a provincial board (buyer) have an effect on every farm in the province. The province of Québec also has a specific agreement through its Ministry of Agriculture in which animal health is promoted through financial support of the delivery of veterinary services (MAPAQ, 2019). This is likely to have an effect on the involvement of veterinarians on farms and perhaps on the farmers' perception of biosecurity.

The sampling frame of this study resulted in a greater proportion of large and loose-housing farms and a smaller proportion of farms from Québec than the proportion in Canada in 2015 (CDIC, 2015). Although there was no association between the perception of biosecurity practices and type of housing, and although only 1 of the biosecurity practices was associated with milk production, the perception of almost all practices was associated with geographical region. This could have influenced the proportion of respondents perceiving the practices as effective. We think, however, that the trends observed in this study are representative of the Canadian dairy farmers because the difference between unadjusted prevalence and prevalence adjusted for region was smaller than $7 \%$ for other parts of this study (J. Denis-Robichaud, unpublished data). It is possible that the proportion of respondents considering biosecurity practices to be effective was greater in the study than in actuality due to the acquiescence bias (i.e., people tend to respond positively to questions more often than they respond negatively; Hinz et al., 2007). This should be considered in the interpretation of these results, but this bias should be minimal because biosecurity is not linked to social desirability or politically sensitive. Additionally, our results are comparable with what was found with a best-worse scaling approach, which has less acquiescence bias (Whitty et al., 2014; Shortall et al., 2017). It is also possible that respondents were more likely to be implementing or have positive attitudes toward biosecurity practices (participation bias). However, the study included multiple management practices, including antimicrobial use, calf health, down cow management, and the role of veterinarians, which likely minimized the effect of participation bias on these results.

Most respondents perceived biosecurity practices as effective, but the adoption of these practices remained limited on their farms. This suggests that other elements that were not measured in the present study could have been in play to explain the low adoption of biosecurity practices. For example, the health belief model suggests that a cue to action is motivated by the belief in effectiveness of a preventive behavior but also 
by the belief in a personal threat (Rosenstock, 1974; Janz and Becker, 1984), which has been suggested to be low for dairy farmers (Nöremark et al., 2010). In the present study, when asked about the effectiveness and importance of general biosecurity, farmers more often perceived general biosecurity as effective rather than important. Moreover, multiple specific biosecurity measures are perceived as impractical to implement (Sayers et al., 2014; Shortall et al., 2017), which can limit the adoption of these practices (Kuster et al., 2015). The respondents' unique contexts, including previous experiences, routines, goals, regulations, and economic, cultural, and family influences, were not measured in the present study but were likely influential in the adoption of different practices (Ritter et al., 2017).

Respondent personality could also play a role in the decision of whether to implement biosecurity practices (Ritter et al., 2017), but it is unclear to what extent. A study in Denmark categorized farmers' attitudes toward biosecurity practices according to their understanding of risks and perception of effectiveness, but none of the different types of farmers implemented the compulsory biosecurity plan (Kristensen and Jakobsen, 2011).

\section{CONCLUSIONS}

Practices involving direct animal-to-animal contact were perceived as being effective by more respondents than practices involving fomites. The perception of many biosecurity practices was associated with their implementation on farm and the involvement of a veterinarian in discussing the practice. Regardless of the perception of general biosecurity as effective and important, the adoption of specific biosecurity practices remained limited. The results support that, for most biosecurity practices, perception of effectiveness does not automatically lead to implementation on dairy farms. It is also possible that involvement of Canadian veterinarians in the discussion about on-farm biosecurity will have an effect on the perception of effectiveness and maybe on the adoption of biosecurity practices.

\section{ACKNOWLEDGMENTS}

This study was funded by the Dairy Cluster 2 Research program through the Canadian Agri-Science Clusters Initiative (Dairy Farmers of Canada, Agriculture and Agri-Food Canada, Canadian Dairy Commission, and Natural Sciences and Engineering Research Council, Ottawa, ON). The authors acknowledge Ashique Rahman (St-Hyacinthe, QC, Canada) and the technical staff and students from the participating Canadian universities (University of Calgary, University of Guelph, Université de Montréal, University of Prince
Edward Island, and University of Saskatchewan) for their contribution to questionnaire building and data collection. Appreciation is extended to the participating dairy farmers and the provincial milk boards for their willingness to contribute to the study.

\section{REFERENCES}

Bauman, C. A., H. W. Barkema, J. Dubuc, G. P. Keefe, and D. F. Kelton. 2018. Canadian National Dairy Study: Herd-level milk quality. J. Dairy Sci. 101:2679-2691. https://doi.org/10.3168/jds .2017-13336.

Brennan, M. L., and R. M. Christley. 2013. Cattle producers' perceptions of biosecurity. BMC Vet. Res. 9:71. https://doi.org/10.1186/ 1746-6148-9-71.

Canadian Dairy Commission. 2016. Supply management. Accessed Jun. 12, 2019. http://www.cdc-ccl.gc.ca/CDC/index-eng.php?link $=114$.

CDIC (Canadian Dairy Information Center). 2015. Overview of the Canadian dairy industry at the farm. Accessed Jan. 8, 2019. http: //www.dairyinfo.gc.ca/index_e.php.

CFIA (Canadian Food Inspection Agency). 2013. Biosecurity for Canadian dairy farms: National standard. CFIA P0836-13. Accessed Jan. 8, 2019. http://www.inspection.gc.ca/animals/terrestrial -animals/biosecurity/standards-and-principles/dairy-farms/eng/ $1359657658068 / 1359658301822$.

Dargatz, D. A., F. B. Garry, and J. L. Traub-Dargatz. 2002. An introduction to biosecurity of cattle operations. Vet. Clin. North Am. Food Anim. Pract. 18:1-5. https://doi.org/10.1016/S0749 $-0720(02) 00002-6$

DFC (Dairy Farmers of Canada). 2018. ProAction-Biosecurity. Accessed Jan. 8, 2019. https://www.dairyfarmers.ca/proaction/ resources/biosecurity.

Dohoo, I. R., S. W. Martin, and H. Stryhn. 2009. Veterinary Epidemiologic Research. 2nd ed. VER Inc., Charlottetown, PE, Canada.

Emanuelson, U., K. Sjöström, and N. Fall. 2018. Biosecurity and animal disease management in organic and conventional Swedish dairy herds: A questionnaire study. Acta Vet. Scand. 60:23. https: //doi.org/10.1186/s13028-018-0376-6.

Gunn, G. J., C. Heffernan, M. Hall, A. McLeod, and M. Hovi. 2008. Measuring and comparing constraints to improved biosecurity amongst GB farmers, veterinarians and the auxiliary industries. Prev. Vet. Med. 84:310-323. https://doi.org/10.1016/j.prevetmed .2007.12.003.

Heffernan, C., L. Nielsen, K. Thomson, and G. Gunn. 2008. An exploration of the drivers to bio-security collective action among a sample of UK cattle and sheep farmers. Prev. Vet. Med. 87:358-372. https://doi.org/10.1016/j.prevetmed.2008.05.007.

Hinz, A., D. Michalski, R. Schwarz, and P. Y. Herzberg. 2007. The acquiescence effect in responding to a questionnaire. Psychosoc. Med. 4:Doc07.

Jansen, J., and T. J. G. M. Lam. 2012. The role of communication in improving udder health. Vet. Clin. North Am. Food Anim. Pract. 28:363-379. https://doi.org/10.1016/j.cvfa.2012.03.003.

Janz, N. K., and M. H. Becker. 1984. The Health Belief Model: A decade later. Health Educ. Q. 11:1-47. https://doi.org/10.1177/ 109019818401100101

Kristensen, E., and E. B. Jakobsen. 2011. Danish dairy farmers' perception of biosecurity. Prev. Vet. Med. 99:122-129. https://doi .org/10.1016/j.prevetmed.2011.01.010.

Kuster, K., M. E. Cousin, T. Jemmi, G. Schüpbach-Regula, and I. Magouras. 2015. Expert opinion on the perceived effectiveness and importance of on-farm biosecurity measures for cattle and swine farms in Switzerland. PLoS One 10:e0144533. https://doi.org/10 .1371/journal.pone.0144533.

Maldonado, G., and S. Greenland. 1993. Simulation study of confounder-selection strategies. Am. J. Epidemiol. 138:923-936.

MAPAQ (Ministère de l'Agriculture, des Pêcheries et de l'Alimentation). 2019. Amélioration de la santé animale au Qué- 
bec (ASAQ). Accessed Jun. 12, 2019. https://www.mapaq.gouv .qc.ca/fr/Productions/md/programmesliste/santeanimale/Pages/ ASAQ.aspx.

Moore, D. A., D. A. Leach, D. Bickett-Weddle, K. Andersen, A. R. Castillo, C. A. Collar, G. Higginbotham, N. Peterson, B. Reed, and M. L. Hartman. 2010. Evaluation of a biological risk management tool on large Western United States dairies. J. Dairy Sci. 93:4096-4104. https://doi.org/10.3168/jds.2010-3272.

Nöremark, M., J. Frössling, and S. S. Lewerin. 2010. Application of routines that contribute to on-farm biosecurity as reported by Swedish livestock farmers. Transbound. Emerg. Dis. 57:225-236. https://doi.org/10.1111/j.1865-1682.2010.01140.x.

R Core Team. 2015. A Language and Environment for Statistical Computing. Foundation for Statistical Computing, Vienna, Austria.

Ritter, C., J. Jansen, S. Roche, D. F. Kelton, C. L. Adams, K. Orsel, R. J. Erskine, G. Benedictus, T. J. G. M. Lam, and H. W. Barkema. 2017. Invited review: Determinants of farmers' adoption of management-based strategies for infectious disease prevention and control. J. Dairy Sci. 100:3329-3347. https://doi.org/10.3168/ jds.2016-11977.

Ritter, C., J. Jansen, K. Roth, J. P. Kastelic, C. L. Adams, and H. W. Barkema. 2016. Dairy farmers' perceptions toward the implementation of on-farm Johne's disease prevention and control strategies. J. Dairy Sci. 99:9114-9125. https://doi.org/10.3168/jds.2016 -10896 .
Rosenstock, I. M. 1974. Historical origins of the Health Belief Model. Health Educ. Monogr. 2:328-335. https://doi.org/10.1177/ 109019817400200403

Sarrazin, S., A. B. Cay, J. Laureyns, and J. Dewulf. 2014. A survey on biosecurity and management practices in selected Belgian cattle farms. Prev. Vet. Med. 117:129-139. https://doi.org/10.1016/j .prevetmed.2014.07.014.

Sayers, R. G., M. Good, and G. P. Sayers. 2014. A survey of biosecurity-related practices, opinions and communications across dairy farm veterinarians and advisors. Vet. J. 200:261-269. https://doi .org/10.1016/j.tvjl.2014.02.010.

Shortall, O., M. Green, M. Brennan, W. Wapenaar, and J. Kaler. 2017. Exploring expert opinion on the practicality and effectiveness of biosecurity measures on dairy farms in the United Kingdom using choice modeling. J. Dairy Sci. 100:2225-2239. https:// doi.org/10.3168/jds.2016-11435.

Shortall, O., A. Ruston, M. Green, M. Brennan, W. Wapenaar, and J. Kaler. 2016. Broken biosecurity? Veterinarians' framing of biosecurity on dairy farms in England. Prev. Vet. Med. 132:20-31. https: //doi.org/10.1016/j.prevetmed.2016.06.001.

Whitty, J. A., R. Walker, X. Golenko, and J. Ratcliffe. 2014. A think aloud study comparing the validity and acceptability of discrete choice and best worst scaling methods. PLoS One 9:e90635. https: //doi.org/10.1371/journal.pone.0090635. 